\title{
An Observed Trend in Central South American Precipitation
}

\author{
Brant Liebmann, ${ }^{*}$ Carolina S. Vera, ${ }^{+}$Leila M. V. Carvalho, ${ }^{\#}$ Inés A. Camilloni, ${ }^{+}$ \\ Martin P. Hoerling, ${ }^{*}$ Dave Allured, ${ }^{*}$ Vicente R. Barros, ${ }^{@}$ Julián Báez, ${ }^{\&}$ And Mario Bidegain** \\ *NOAA-CIRES Climate Diagnostic Center, Boulder, Colorado \\ ${ }^{+}$Centro de Investigaciones del Mar y la Atmósfera (CIMA-CONICET/UBA), and Department of Atmospheric and Oceanic Sciences, \\ University of Buenos Aries, Buenos Aries, Argentina \\ \#Department of Atmospheric Sciences, Institute of Astronomy and Geophysics, University of São Paulo, São Paulo, Brazil \\ ${ }^{\circledR}$ Department of Atmospheric and Oceanic Sciences, University of Buenos Aries, Buenos Aries, Argentina \\ ${ }^{\&}$ Dirección de Meteorologia e Hidrologia, and Dirección Nacional de Aeronautica Civil (DINAC), Luque, Paraguay \\ **Facultad de Ciencias, Universidad de la República, Montevideo, Uruguay
}

(Manuscript received 15 January 2004, in final form 26 May 2004)

\section{ABSTRACT}

\begin{abstract}
Seasonal linear trends of precipitation from South American station data, which have been averaged onto grids, are examined, with emphasis on the central continent. In the period 1976-99, the largest trend south of $20^{\circ} \mathrm{S}$ occurs during the January-March season, is positive, and is centered over southern Brazil. From 1948 to 1975 the trend is also positive, but with less than half the slope. The trend is not due to a systematic change in the timing of the rainy season, which almost always starts before January and usually ends after March, but rather results from an increase in the percent of rainy days, and an increase in the rainy day average. The dynamic causes of the trend are not obvious. It does not appear to be accounted for by an increase in synoptic wave activity in the region. The precipitation trend is related to a positive sea surface temperature trend in the nearby Atlantic Ocean, but apparently not causally. The trend in the Atlantic seems to result from a decrease in mechanical stirring and coastal upwelling associated with a decrease in the strength of the western edge of the circulation associated with the South Atlantic high.
\end{abstract}

\section{Introduction}

This paper is a report on a study of observed precipitation trends in central South America. In particular, we identify a positive wet season trend centered in southern Brazil that seems to be quite robust. Central South America is of particular interest because it is the most densely populated and agriculturally productive region of the continent.

One of the main motivations for the research presented here is an apparent change that has occurred in river discharge. Genta et al. (1998), using 30-yr-averaged streamflows, found that flows have increased from the 1960s through the end of the record in the mid1990s in the Paraná, Paraguay, and Uruguay Rivers. Together these rivers drain most of the La Plata Basin of central South America. Robertson and Mechoso (1998), using annual average discharges, found a marked trend in the Paraná and Paraguay Rivers, as well as evidence of decadal variability. They found that discharge increased rapidly from about 1960 to 1980, and

Corresponding author address: Brant Liebmann, NOAA-CIRES Climate Diagnostics Center, R/CDC1, 325 Broadway, Boulder, CO 80305-3328.

E-mail: Brant.Liebmann@NOAA.gov then leveled off until their end of record in 1992. They noted that the trends appear to be coincident with trends in global sea surface temperature (SST).

Importantly, incidences of flooding also appear to be on the rise. This is the case, for example, at the river gauging station at Corrientes, Argentina, which is located just downstream of the confluence of the Paraguay and Paraná Rivers. Together, these rivers drain an area of 2.6 million $\mathrm{km}^{2}$, stretching over much of central South America east of the Andes Mountains, including parts of Bolivia and northern Argentina, all of Paraguay, and much of southeastern Brazil. The flow at Corrientes is of particular interest because that point divides the upper and middle Paraná basins (Tossini 1959). The upper basin lies mostly in areas with relatively steep terrain, which promotes rapid runoff, while the middle and lower basins are nearly flat and subject to extended and damaging flooding. Water resulting in all the extreme flooding events of the last century in the middle and lower Paraná basins fell as rainfall in the upper basin (Camilloni and Barros 2003).

If a flooding event at Corrientes is defined as a monthly flow anomaly of more than two standard deviations above each month's climatology, then there were almost 6 times as many flood months in the $20 \mathrm{yr}$ from 1980 to 1999 as there were in the $60 \mathrm{yr}$ from 1920 to 1979 
(Camilloni and Barros 2003). Thus, an examination of rainfall trends in the region is in order.

While rainfall and river discharge are related, both quantities contain unique information. River discharge is an integrated quantity that yields the gross sense of variations in rainfall, and its records tend to be long. On the other hand, rainfall, with sufficient station density, can fill in details about regional variations. Further, the temporal relationship between rainfall and flow can vary, depending on many variables such as slope of the terrain, size of the catchment, and type of soil (e.g., Chow et al. 1988). A further interesting difference between rainfall and river flow is that the percent change in river flow tends to be amplified compared to that in rainfall (Chiew et al. 1995; Berbery and Barros 2002).

Barros et al. (2000) pointed out that besides being detrimental, trends in rainfall may be beneficial as well. They observed positive trends of precipitation over most of Argentina from 1916 to 1991. While the increase in catastrophic flooding of the low lands of the Paraná basin was noted, there has also been a westward expansion of agricultural activity in the semiarid zone of Argentina.

\section{Data}

The basis of this study is a set of daily rainfall observations in South America from several different sources (see the acknowledgments). The station records have been quality controlled to some extent, initially by the providers. Additional screening has eliminated suspected multiday accumulations and unconfirmed daily values higher than reasonable thresholds. These data are analyzed either as a group of individual stations, or after first averaging them onto grids of varying resolution. Values at grid points are unweighted averages of all stations within a radius in coordinate space of three quarters of the resolution of the grid (e.g., points at a grid spacing of $2.5^{\circ}$ will include an average of all stations within a radius of $1.875^{\circ}$ from the point). Therefore some stations are included in the averages for two or more grid points, resulting in a weak spatial smoothing.

Unless stated otherwise, observations from a station are included if that station reported at least $4 \mathrm{yr}$ of data with no more than $33 \%$ missing values in available years. A total of 5,825 stations met these requirements. They have an average record length of $15 \mathrm{yr}$, with $6.1 \%$ of data missing in years with data. Although this method results in the inclusion of different data in each period, which is generally not recommended for trend studies, the high density of stations minimizes any possible problem. This claim is corroborated, as will be shown, when trends are computed after averaging only nearly complete series. In some areas station density increases beginning in the mid-1970s; thus, the focus of this study is 1976-99. In some key locations, however, plentiful data extend back to the 1940s.

The analysis of rainfall is augmented by meteorolog-

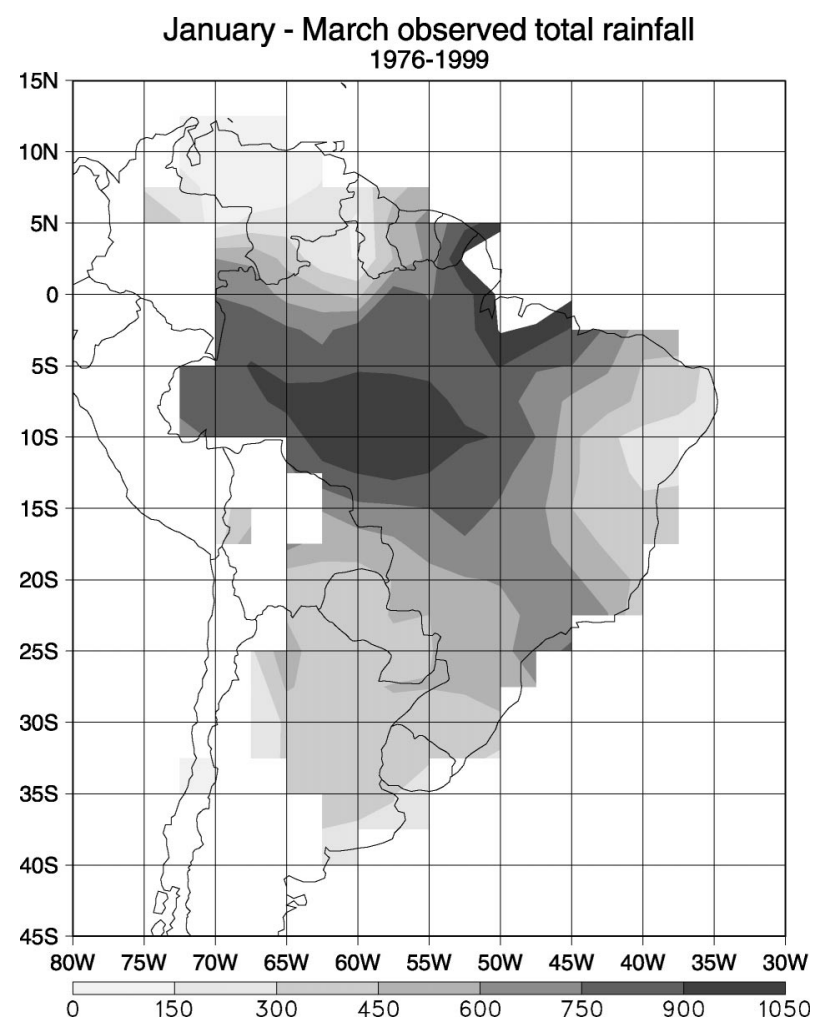

FIG. 1. The 1976-99 JFM climatological precipitation (mm season ${ }^{-1}$ ) on a $2.5^{\circ}$ grid. Area near $0^{\circ} 50^{\circ} \mathrm{W}$ is above the range of shading. Areas without data are left blank.

ical and SST fields from the National Centers for Environmental Prediction-National Center for Atmospheric Research (NCEP-NCAR) 40-Year Reanalysis Project. Satellite data were assimilated into the reanalysis products from the late 1970s, which has improved their accuracy, especially in the data-sparse regions of the Southern Hemisphere (Mo et al. 1995).

\section{Results}

\section{a. Precipitation climatology and trends}

Figure 1 shows the January-March (JFM) climatological precipitation total. The local maximum in the southern Amazon is near its southernmost position in the annual cycle, slightly north of the December-February (DJF) position. The largest seasonal total is centered on the equator at the eastern edge of the continent. This maximum is associated with the continental extension of the Atlantic intertropical convergence zone (ITCZ). The South Atlantic convergence zone (SACZ) is manifested as a broad band of increased rainfall extending southeastward from the precipitation maximum in the southern Amazon basin.

The linear trend of JFM seasonal total precipitation from 1976 to 1999 is shown in Fig. 2a. In this study, trend is defined as the slope of the best-fit straight line of the data at each grid point, and is computed by the 
January - March precipitation trend 1976 - 1999
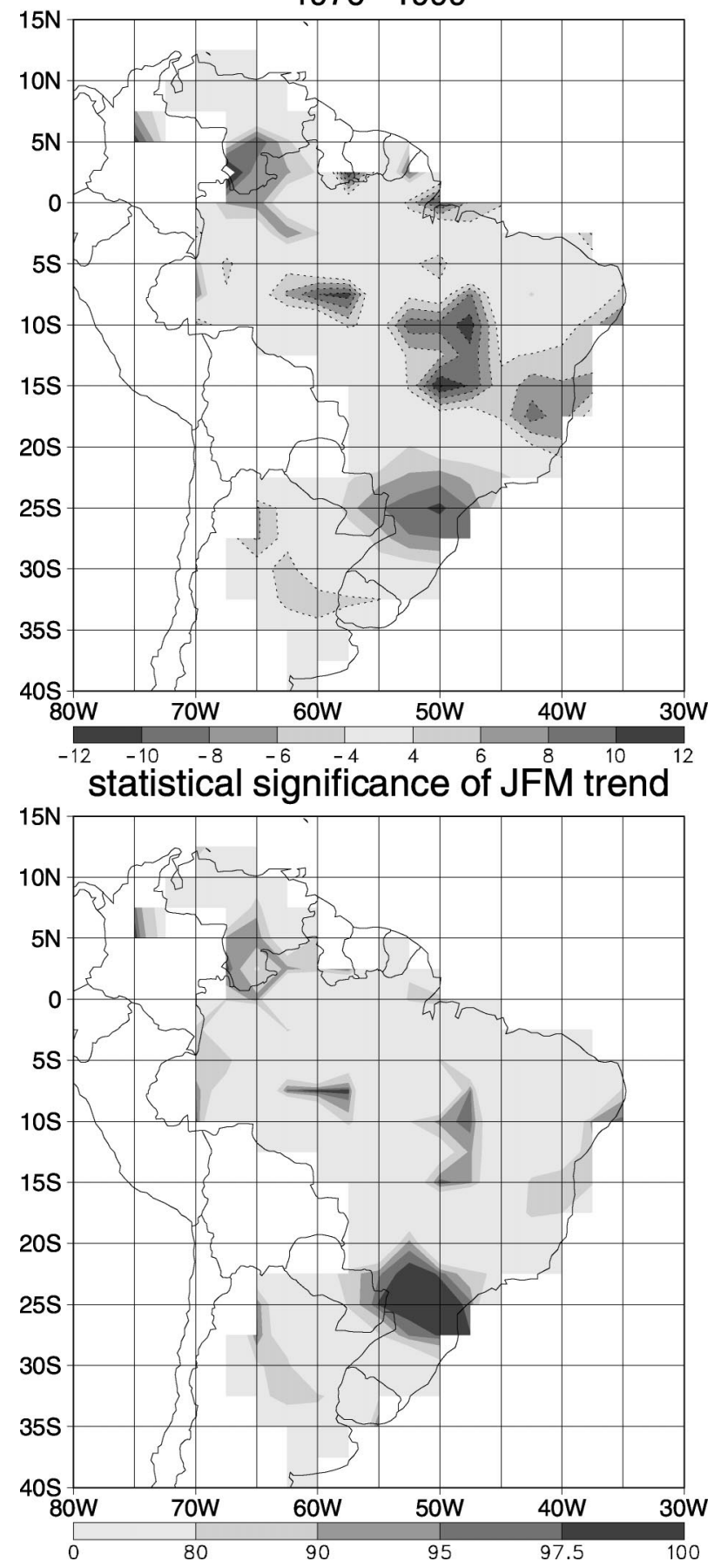

FIG. 2. (a) linear trend in mm season ${ }^{-1}$ of JFM total precipitation from 1976 to 1979 . Negative trends are indicated with both shading and dotted contours. (b) Statistical ranking of observed JFM trend compared with randomizations (see text for explanation of technique). method of least squares. A spatially coherent center with a large positive trend is centered at $25^{\circ} \mathrm{S}, 50^{\circ} \mathrm{W}$. A larger area with a negative trend, roughly coinciding with the north flank of the SACZ, is farther north. In NovemberJanuary (NDJ) and especially in DJF (1976/771998/99), both of which are not shown, the negative trend near the SACZ is somewhat larger than in JFM, while the trend in southern Brazil is largest of any 3month season during JFM.

To estimate statistical significance, 3-month JFM totals for each of the years were randomly shuffled 999 times and the absolute value of the trend calculated at each point for each randomization. Figure $2 \mathrm{~b}$ shows the ranking of the absolute value of the observed trend relative to the randomizations. The one area of obvious statistical relevance is associated with the positive trend in southern Brazil, which is the area of focus in this study. (Both DJF and NDJ show larger statistical relevance in the region with a negative trend north of the SACZ than is apparent in JFM.)

Figure 3 a shows the monthly climatology of rainfall in southern Brazil. Hereafter the southern Brazil index is considered to be an average of values on a $1^{\circ}$ grid, including the grid points centered from $23^{\circ}-29^{\circ} \mathrm{S}, 47^{\circ}-$ $53^{\circ} \mathrm{W}$. Precipitation peaks in January, followed by February, December, and March.

In Fig. $3 b$ the southern Brazil index for JFM is plotted as a function of year. The linear trend is 7.9 mm season ${ }^{-1}$, which represents about a $40 \%$ increase in the expected seasonal precipitation in 1999 relative to 1976 . The trend explains $35 \%$ of the variance. If the outlying year of 1979 is removed, the trend is still $6.7 \mathrm{~mm}$ season $^{-1}$. The JFM seasonal trend results largely from the months of January and February, during which the monthly trends were 3.9 and $3.2 \mathrm{~mm}$ season $^{-1}$. The March trend is $0.2 \mathrm{~mm}$ season ${ }^{-1}$, while that during December is $-1.2 \mathrm{~mm}$ season ${ }^{-1}$-thus, the present focus on the January-March season.

\section{b. Characteristics of precipitation trend}

The rainy season is of course made up of discrete precipitation events. It is of interest to determine the characteristics of the observed trend of increasing seasonal precipitation in southern Brazil. That is, whether there has been a temporal shift in the rainy season, more days with recorded precipitation, increased amounts per rain event, etc. For this part of the study we utilize data from the 110 individual stations within a $2^{\circ}$ radius of $25^{\circ} \mathrm{S}, 50^{\circ} \mathrm{W}$ that contain at least $20 \mathrm{yr}$ of data from 1976 to 1999 . During years with data (22 on average), $2.2 \%$ of the observations were missing during JFM.

The use of individual stations rather than gridded averages has the advantage of being able to record point amounts rather than area averages, but the disadvantages of unequal weighting of the area. The use of individual stations weights the index toward southern São Paulo state, which has a high density of stations. The average 


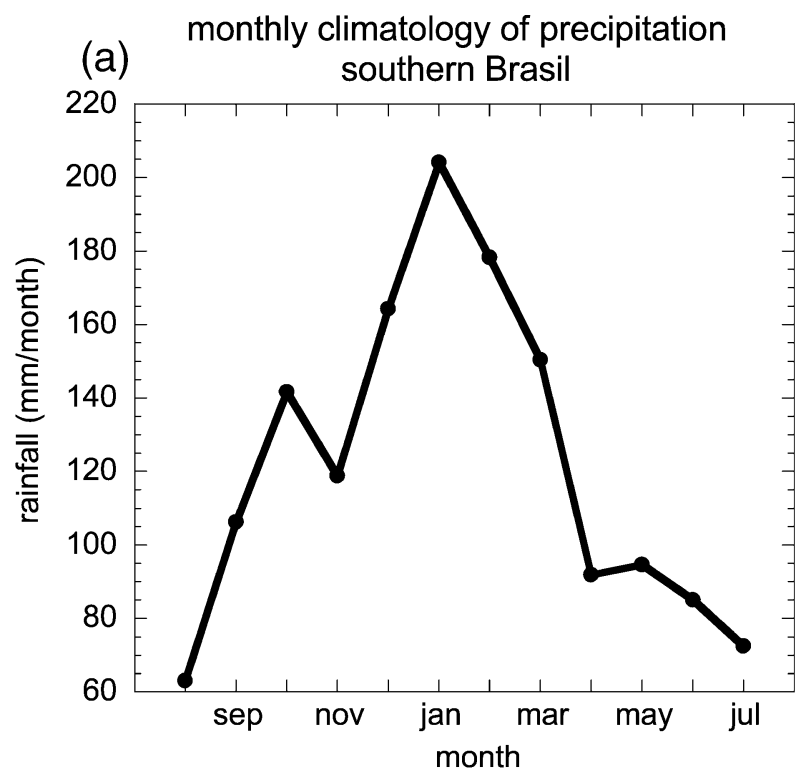

(b) JFM rainfall in southern Brazil versus year

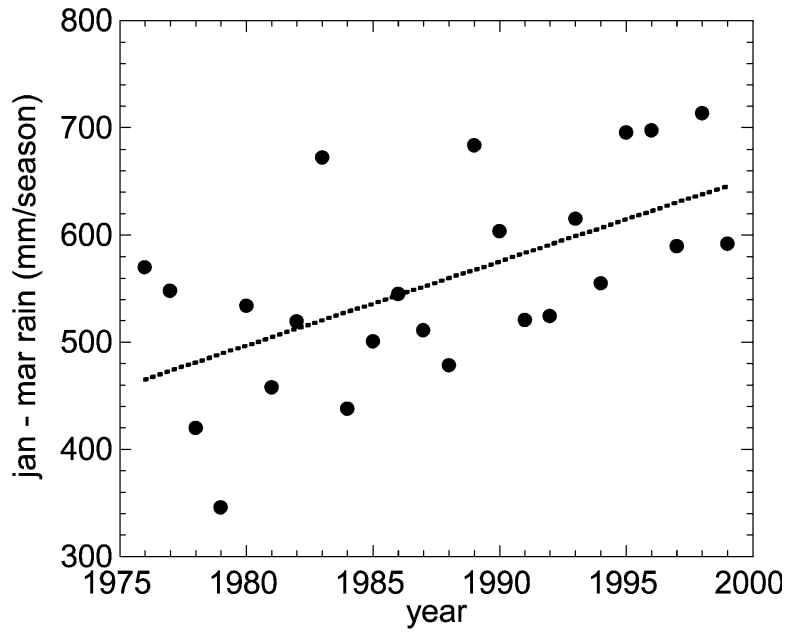

FIG. 3. (a) Climatology of monthly rainfall in southern Brazil (mm month ${ }^{-1}$ ). (b) JFM rainfall (in mm season ${ }^{-1}$ ) in southern Brazil vs year. Dashed curve represents linear, least squares fit.

of the stations exhibits a positive trend of $10.89 \mathrm{~mm}$ per JFM season.

The standardized 24-yr-trends at each of the 110 stations, shown as a percent of that station's standard deviation, are shown in Fig. 4. A total of 106 stations exhibit positive trends, with an average value of 1.62 standard deviations.

Onset and end of the rainy season are determined by Eq. (1) of Liebmann and Marengo (2001):

$$
A(\text { day })=\sum_{n=\text { day }_{0}}^{\text {day }}[R(n)-\bar{R}],
$$

where $R(n)$ is the daily climatological (or that of a particular year) rainfall as a function of day of year, $\bar{R}$ is the annual mean daily rain rate, and day ${ }_{0}$ is the starting

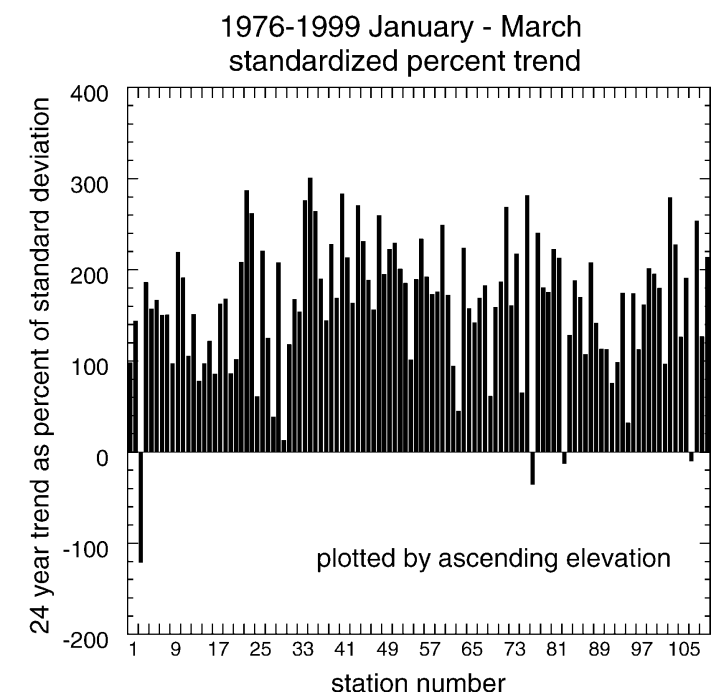

FIG. 4. The JFM trend for each of the 110 stations with at least $20 \mathrm{yr}$ of data for the period 1976-99, expressed as a percent of each station's standard deviation. The stations are plotted in order of ascending elevation, which ranges from 5 to $1140 \mathrm{~m}$.

day of the summation, generally well within the dry season. If in every region of interest the rainy season is considered to be the period during which rainfall exceeds its climatological annual average, then a positive slope indicates the rainy season. Note that this definition is local because it depends upon the climatology in the area of interest.

Figure 5a shows a composite average of all years relative to the onset and end of the rainy season. Each year's time series is obtained by averaging over the 110 stations in southern Brazil. There is a dramatic change of precipitation on the onset and end dates, indicating that Eq. (1) is adequate for defining the onset and end of the rainy season.

In Fig. 5b, daily rainfall, averaged over the southern Brazil stations, for a few individual years are plotted relative to onset. The driest JFM season of the record is 1979,1995 is the wettest, and 1992 represents a "typical" season, although in some years there are larger events prior to the onset of the rainy season than there were during 1992. It is interesting that the driest year, 1979 , is characterized by the largest events, at least during the first 20 days of the rainy season (which occur before January).

In southern Brazil the average onset date is 26 October, with a standard deviation of 50 days. Thus there are only a few (four) seasons in which onset occurs between January and March. The average ending date is 9 April, with a standard deviation of 43 days. Although in several years ending dates lie within JFM, the trend of the end date is toward an earlier end, which would reduce JFM totals. Therefore it appears that no systematic shift in the timing of the rainy season is responsible for the observed trend in southern Brazil JFM rainfall. 

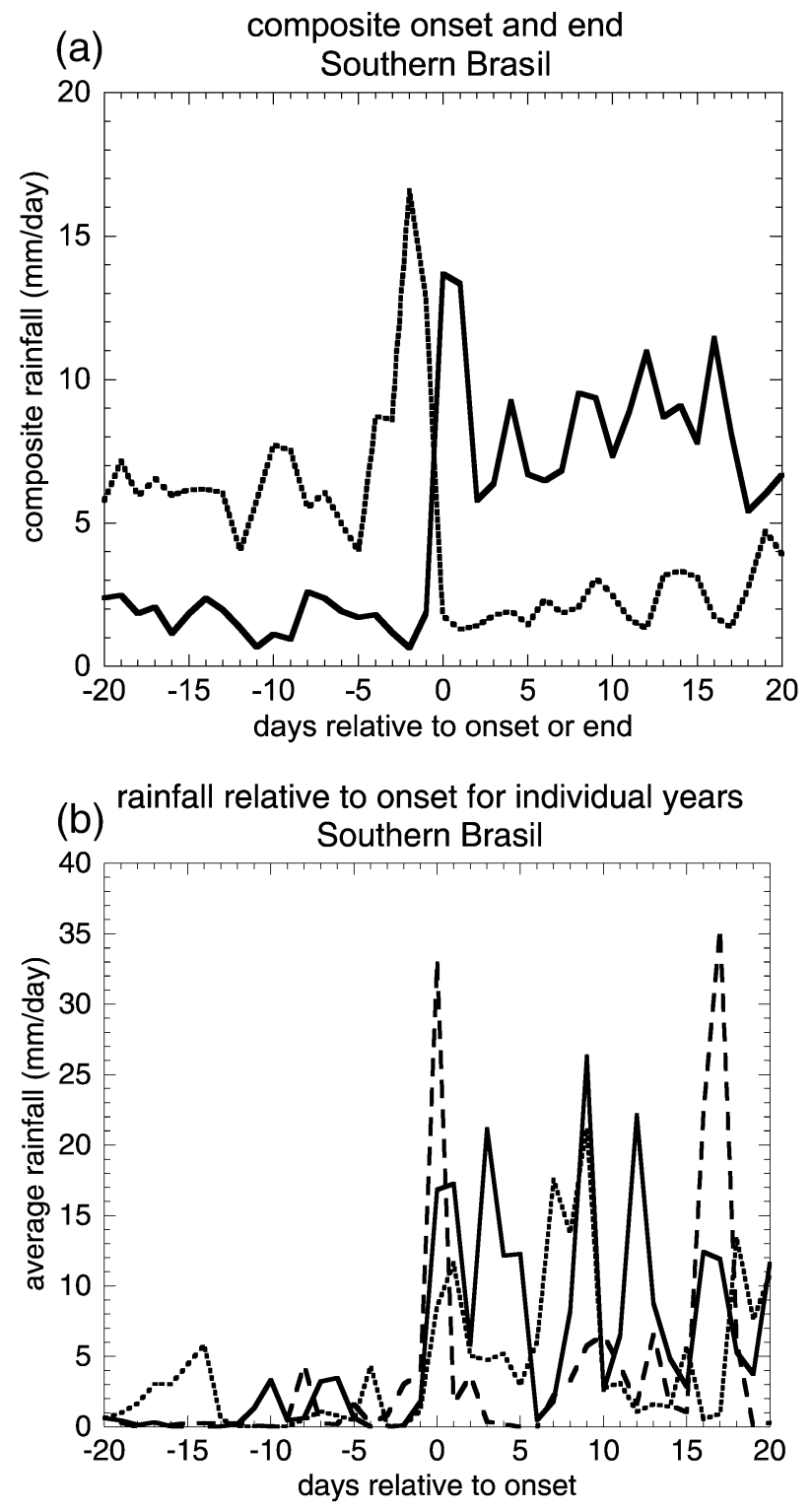

FIG. 5. (a) Composite onset (solid curve) and end (dotted curve) from average of stations centered at $25^{\circ} \mathrm{S}, 50^{\circ} \mathrm{W}$. Onset and end of

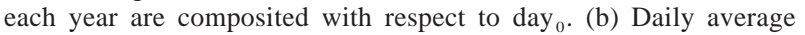
rainfall from stations for 1979 (dashed curve; driest JFM on record), 1992 (solid curve; near-average JFM), and 1995 (dotted curve; wettest JFM on record). Year is that in which JFM lies.

There is a steady increase in the average daily rain rate of about $0.08 \mathrm{~mm} \mathrm{day}^{-1}$ season $^{-1}$ during the rainy season (defined each year by the varying starting and ending dates). This appears to be the result of both an increase in the number of days with rainfall during the rainy season, and in the amount per event. Individual stations are averaged for January and February for the first (1976-81) and last (1994-99) 6-yr segments. In each of the years considered, the rainy season has started by 1 January. In all except two years (1981 with and ending date of 26 February, and 1997 with an ending

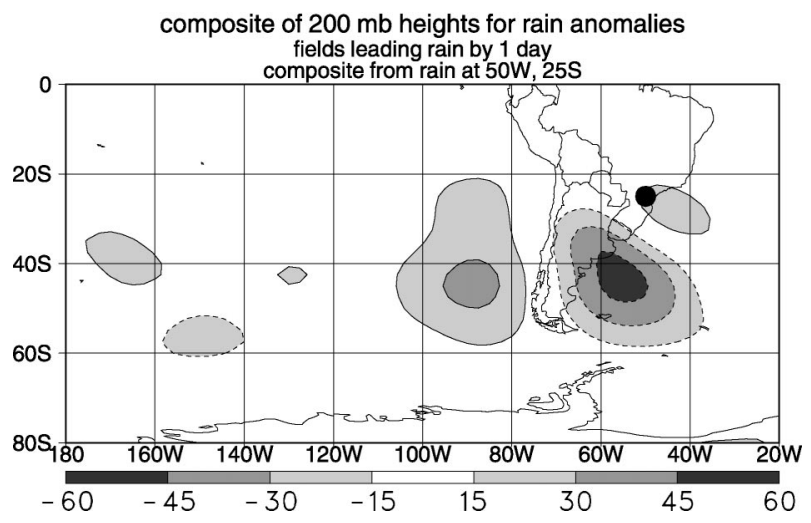

FIG. 6. Composite of 200-mb anomalies (from JFM 1976-99 average) based on 197 large rainfall events in southern Brazil. Rainfall events are determined from an average of grid points in the same area as described in the discussion of Fig. 3 (dot indicates center), except that only stations with at least $20 \mathrm{yr}$ of data from 1976 to 1999 were used in the computation of the gridded values. Events are days with maximum precipitation of any excursion above 1 std dev above the JFM climatology. Scale is in geopotential meters. Negative contours are dotted.

date of 24 February) the rainy season extended past the end of February. From 1976 to 1981, on average over all the stations, it was dry at an individual station on $52.2 \%$ of the days and the average rainfall on a rainy day was $14.8 \mathrm{~mm}$. From 1994 to 1999 it was dry $46.0 \%$ of the days, with a rainy day average of $17.5 \mathrm{~mm}$.

As a percent of rainy days, events of almost every amount more than $12 \mathrm{~mm}$ increased during 1994-99 as compared to 1976-81, including heavy, or "extreme" daily precipitation events. For example, in the average of the early years there was an $18.3 \%$ chance during a rainy day of a 100-mm event in January and February at 1 of the 110 stations in a given year. During the later $6 \mathrm{yr}$ the chances more than doubled, to $38.2 \%$.

\section{c. Synoptic forcing of precipitation in southern Brazil}

Figure 6 shows the composite 200-mb anomalous height pattern 1 day prior to large daily rainfall events (defined in caption) in southern Brazil. The dominant pattern appears to be that of a synoptic-scale wave train propagating into the area from the Pacific Ocean. The pattern is similar to that determined by other studies to be relevant to the forcing of precipitation anomalies in the SACZ and downstream of the South American lowlevel jet stream (e.g., Salio et al. 2002; Liebmann et al. 2004). The anomalies are weak, suggesting that while this pattern is dominant, it is somewhat washed out due to interevent variability. There are only subtle differences in the center of the low to the southwest of the rainfall anomaly when either the first or last $6 \mathrm{yr}$ of the record are used in constructing composites.

The trend in 200-mb heights is shown in Fig. 7, along with an estimate of statistical significance. There is little to indicate a systematic deepening in the synoptic-scale 


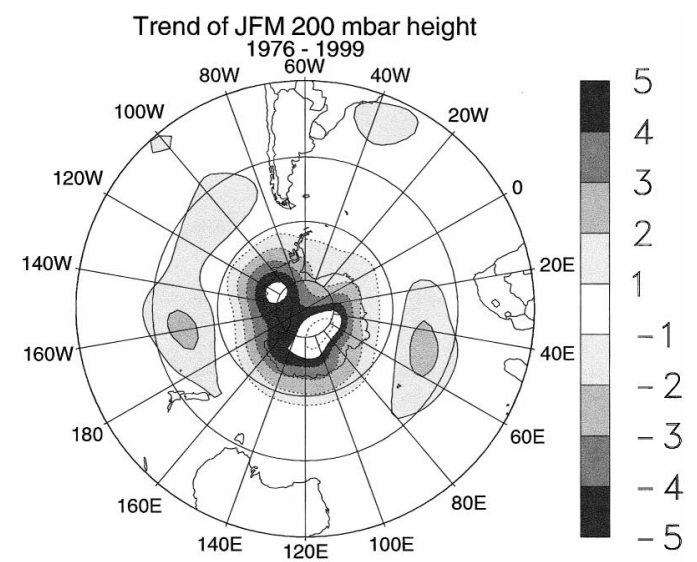

Statistical significance of trend of JFM 200 mbar height

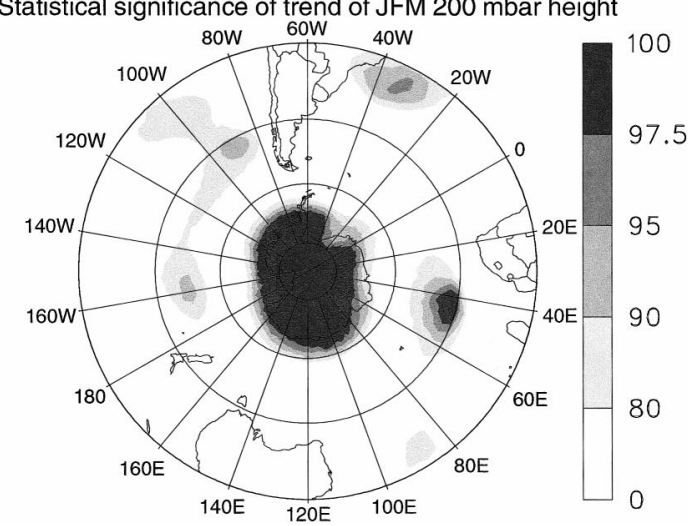

FIG. 7. (a) Linear trend of JFM average 200-mb geopotential height from 1976 to 1999. Scale is in $\mathrm{m}^{\text {season }}{ }^{-1}$. Negative contours are dotted. (b) Estimate of statistical significance of trend in (a). For explanation of method of estimating significance see discussion of Fig. 2b. Edge of plot is at $20^{\circ} \mathrm{S}$.

trough upstream of southern Brazil. The largest and most significant trends appear south of about $70^{\circ} \mathrm{S}$, where, according to the reanalysis, heights have systematically decreased. Marshall (2002) found little support for this trend in a direct comparison with radiosonde measurements, although the radiosondes are located largely around the perimeter of the region in which the reanalysis shows a trend. More recently, Marshall (2003), using six surface stations to develop a proxy for the equivalent barotropic Southern Hemisphere annular mode, found the trend of a deepening polar low to be statistically significant and largest in summer (as opposed to that determined in the reanalysis, which indicates it is largest during winter), with the most rapid deepening occurring since the mid-1970s.

In an attempt to determine whether systematic changes in the midlatitude storm track are implicated in the observed trend in precipitation in the area of interest, trends in the 200-mb daily standard deviation (computed for each JFM season) of geopotential heights and seasonal averages of 850-mb daily heat flux anomalies were calculated (not shown). Both the upper-level standard deviations and lower-level season average heat fluxes have increased along a zonal track near $50^{\circ}-60^{\circ} \mathrm{S}$, suggesting an increase in either the strength or frequency of storms in the zonal direction. On the other hand, along the equatorward-propagating track that affects rainfall in the vicinity of the observed trend there is neither an increase in the 200-mb standard deviation nor a significant correlation between variations of synoptic wave heat fluxes and precipitation anomalies. Thus, from a synoptic perspective, the cause of the trend is not obvious.

\section{d. Relation between southern Brazil precipitation trend and SST}

The simultaneous correlation between JFM southern Brazil precipitation and SST is shown in Fig. 8. Correlations with SST in the equatorial Pacific are small, and thus the observed trend does not appear to be associated with the large and frequent El Niños of the 1980s and 1990s. While El Niño has been associated with increased rainfall in southern Brazil and Uruguay (e.g., Pisciottano et al. 1994; Grimm et al. 2000), its influence changes rapidly from month to month (Grimm 2003) and overall is not strong during the JFM season. Figure 9, which shows the simultaneous correlation between SST in Niño-3.4 (see caption for index definition) and rainfall for JFM, reveals only weak correlations away from the equator, and positive correlations do not improve when SST leads rainfall. Further, the 1976-99 trend in JFM Niño-3.4 SST is only $0.005^{\circ} \mathrm{C} \mathrm{yr}^{-1}$.

The SST that is best correlated with southern Brazil precipitation lies in the Atlantic near the east coast of Brazil, slightly north of the center of the rainfall trend. If each year's data were temporally independent, the probability of a correlation as large as that observed occurring by chance is highly unlikely.

Doyle and Barros (2002) examined the relationship between SST in the subtropical Atlantic and precipitation in subtropical South America using a canonical correlation analysis. During January, the maximum SST loading is quite close to that shown in Fig. 8 (and is farther east when DJF averages are used), but the increase of precipitation coincident with warm SST is centered farther south than the location with the largest precipitation trend shown in this paper. The point of maximum precipitation trend shown here is approximately at a node in the north-south pattern in precipitation shown in Doyle and Barros (2002).

Figure 10a shows the linear trend in JFM SST from 1976 to 1999 . A positive trend in the same area as the positive interannual correlation shown in Fig. 8 seems to be statistically relevant (Fig. 10b). The area with a positive trend is not of large enough scale to be revealed prominently by an empirical orthogonal function (EOF) analysis of the entire basin (e.g., Venegas et al. 1997). It is not clear whether the observed correlation is indicative of an interannual relationship between rainfall and SST, or whether it is caused by a coincident trend 


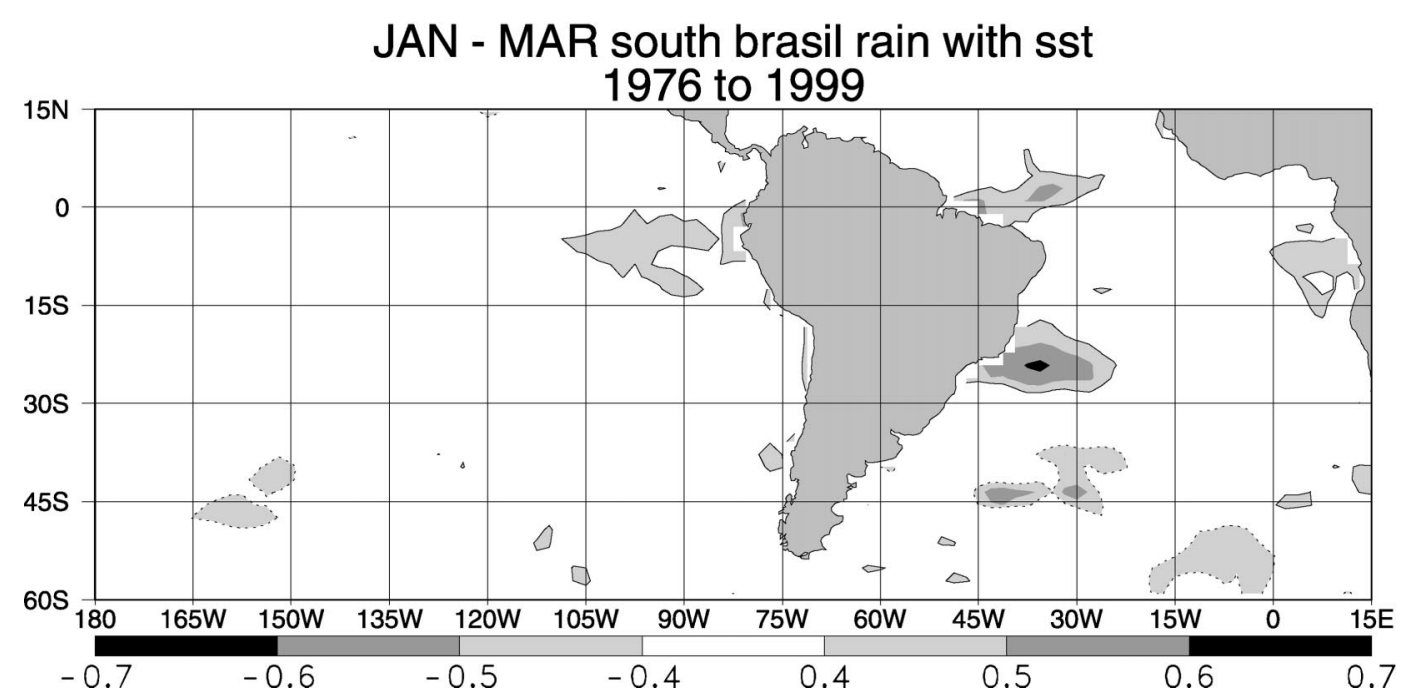

FIG. 8. Simultaneous correlation between JFM SST and gridded southern Brazil rainfall index. Positive correlations outlined by solid curve and negative correlations outlined by dotted curve.

in both fields, effectively reducing the degrees of freedom to 1 .

A reexamination of the rainfall record reveals that, unlike most available South American data, there are several dozen stations in the "southern Brazil" area that have nearly continuous records from 1948 (when the SST data begins) through 1999. Figure 11a is similar

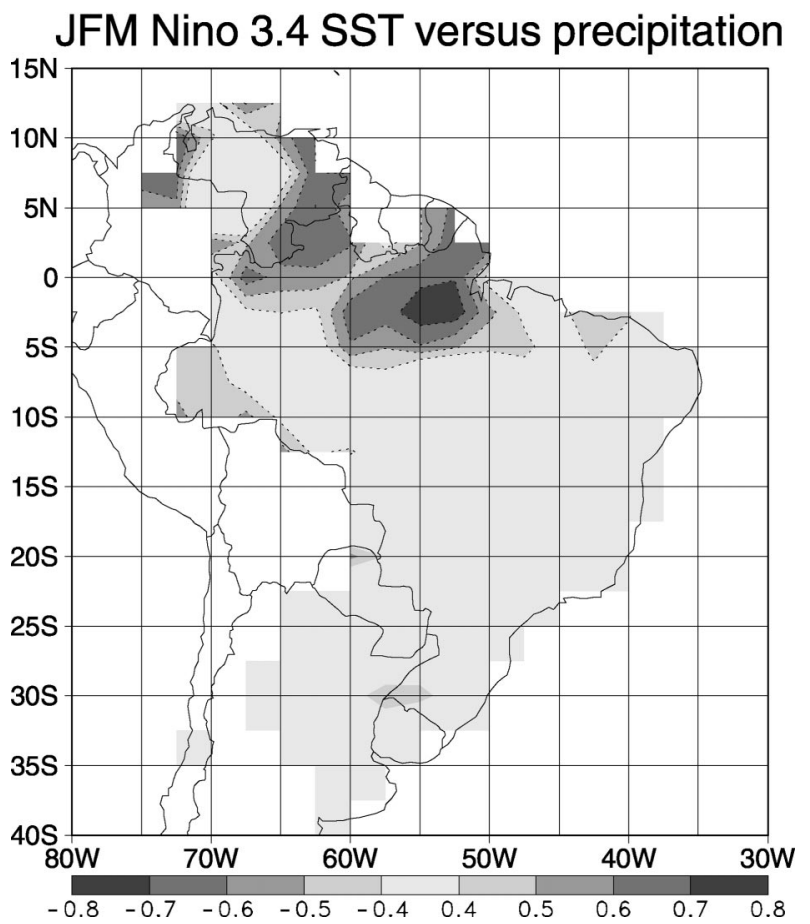

FIG. 9. Simultaneous correlation between JFM SST in Niño-3.4 $\left(5^{\circ} \mathrm{N}-5^{\circ} \mathrm{S}, 170^{\circ}-120^{\circ} \mathrm{W}\right)$ and precipitation for the period $1976-99$. Negative correlations are indicated with both dotted contours and shading. to Fig. 3b, except that the period is longer and that only stations with at least $48 \mathrm{yr}$ of data between 1948 and 1999 were included in the gridded fields from which the index was computed. In total, 41 stations, with an average record length of $50 \mathrm{yr}$, qualify, and those stations have missing observations during JFM on an average of $1.8 \%$ of days. (The correlation between the original gridded and modified JFM indices is 0.97 ; hereafter, the modified version will be used as the southern Brazil index.) For the period 1948-99 (1976-99), 38 (40) of 41 stations show a positive trend with an average trend of 0.91 (1.7) standard deviations per 52 (24) seasons.

Figure 11a shows a dramatic change in the precipitation trend between the 1948-75 and the 1976-99 periods. The trend increased from $2.7 \mathrm{~mm}$ season ${ }^{-1} \mathrm{yr}^{-1}$ in the former to $7.5 \mathrm{~mm}$ season ${ }^{-1} \mathrm{yr}^{-1}$ in the later period. (The 1948-99 trend was $2.4 \mathrm{~mm}^{-1}$ season $^{-1}\left(\mathrm{yr}^{-1}\right)$.) Further, the trend in the later period explains $31 \%$ of the seasonal variance, compared to $12 \%$ in the early period.

The division of the record into pre-1976 and post1975 was chosen because in certain areas the number of stations increases in the mid-1970s. When the Solow change point model (Solow 1987) was applied to the time series, however, the change point in the series was identified with 95\% certainty as occurring near 1978. Thus the original choice of segments appears to be fortuitous.

The large fraction of the precipitation in the area of southern Brazil with the trend falls into the Iguazú basin, which is a tributary of the Paraná River. As a crossvalidation, it is of interest to compare rainfall with river discharge of the Iguazú near the confluence of the Paraná. Figure $11 \mathrm{~b}$ shows such discharge rates for JFM, which have been "naturalized" to remove variations caused by storage. Although Berbery and Barros (2002) 


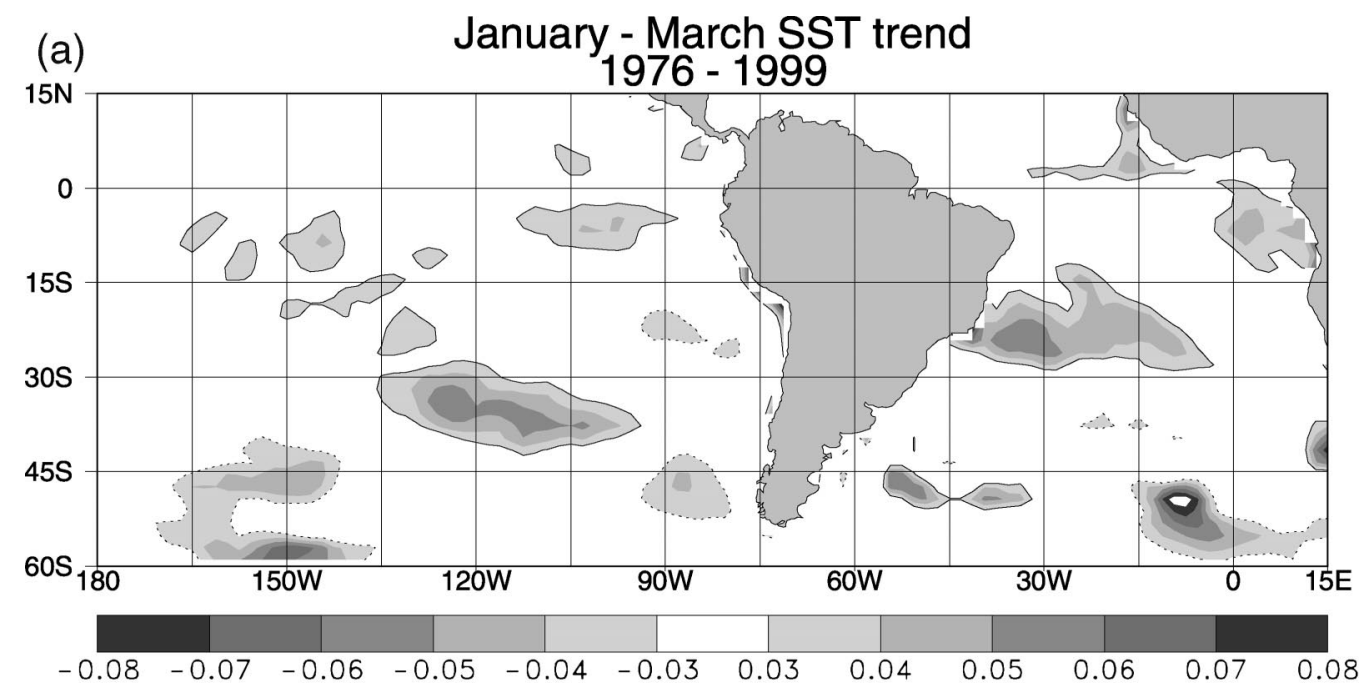

(b) statistical significance of SST trend

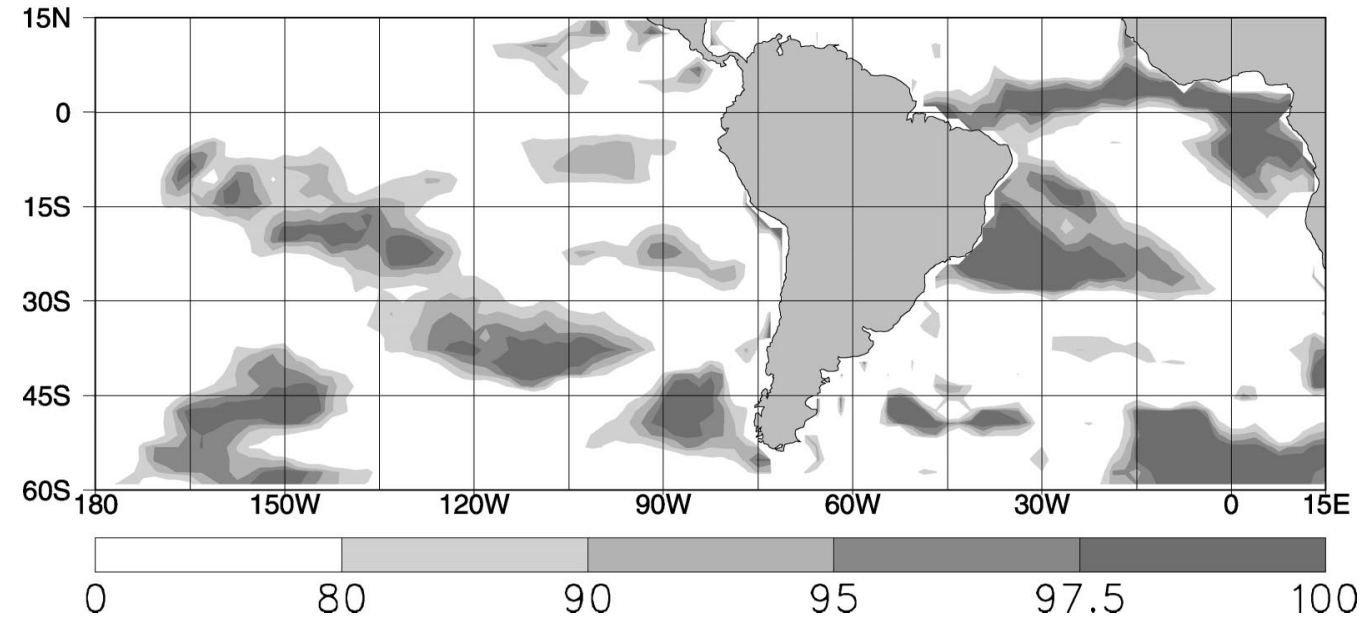

FIG. 10. (a) Linear trend in JFM SST from 1976 to 1999. Positive correlations outlined by solid curve and negative correlations outlined by dotted curve. (b) Estimate of statistical significance of trend in (a). For explanation of method of estimating significance see discussion of Fig. $2 b$.

showed that there tends to be a month's delay between peak rainfall and peak discharge, in a small basin like the Iguazú the delay is expected to be less. The discharge record shows a qualitatively consistent pattern with that in rainfall: an upward trend during both periods, but larger during the later part of the record. It is interesting that during 1976-99 mean precipitation has increased by $35 \%$ (along the trend line), while discharge increased by $161 \%$. This amplification of discharge compared to rainfall has been noted in other basins of South America by Berbery and Barros (2002).

A discharge trend similar to that of the Iguazú River is observed in the upper Paraná basin (not shown), even though most of the contributing basin is on the western fringe of the area that exhibits the largest rainfall trend. The trend in the Paraná is similar in that in the Iguazú in that it is positive in both segments, but nearly double in the later segment as compared to the first. Owing to a larger basin, however, the best similarity occurs with a 1-month delay (February-April). These observed trends appear to be consistent with the findings of Robertson and Mechoso (1998), who found nonlinear (larger in the post-1950 part of the record) positive trends in both the Paraná and Paraguay Rivers. An exact com- 

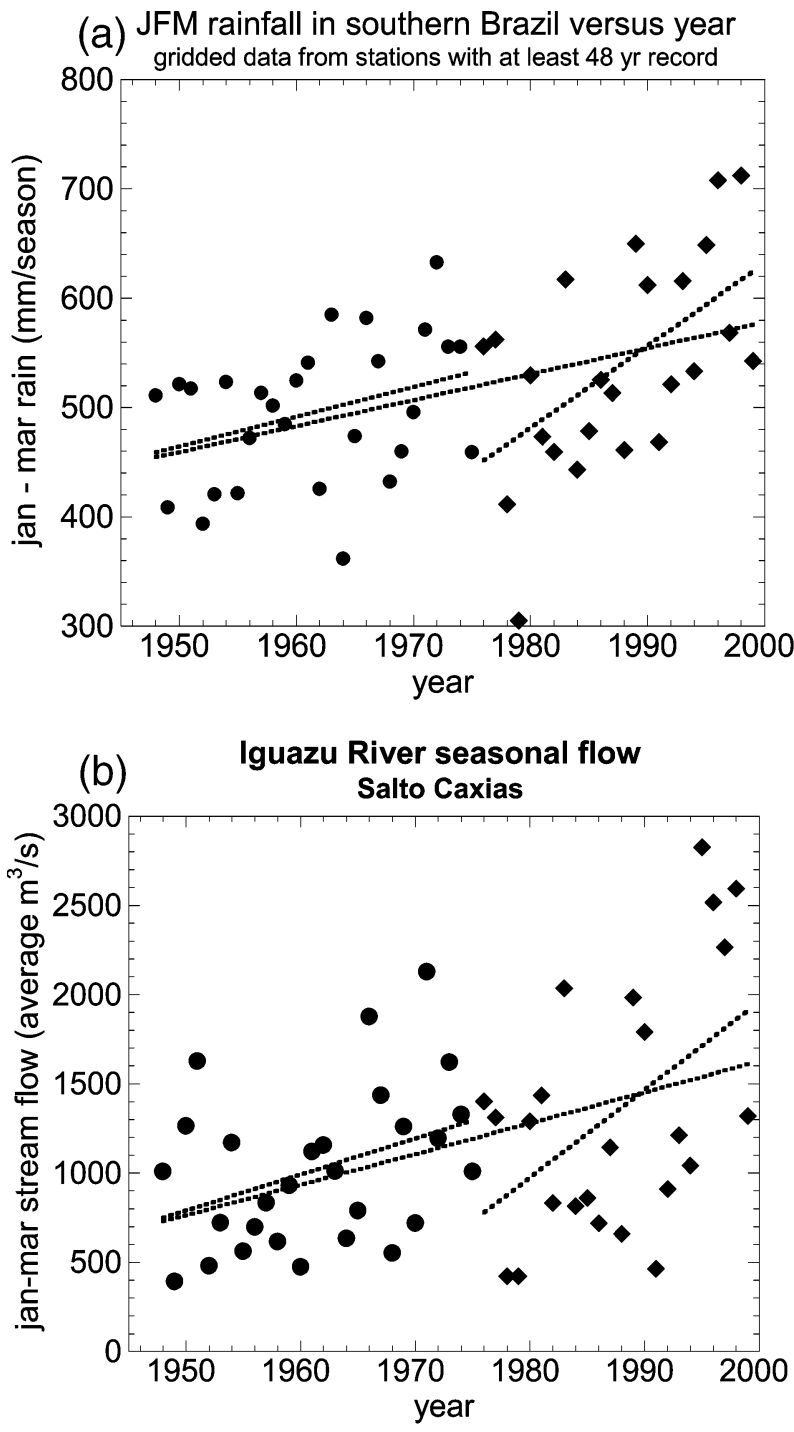

(c) JFM SST in southwestern Atlantic versus year

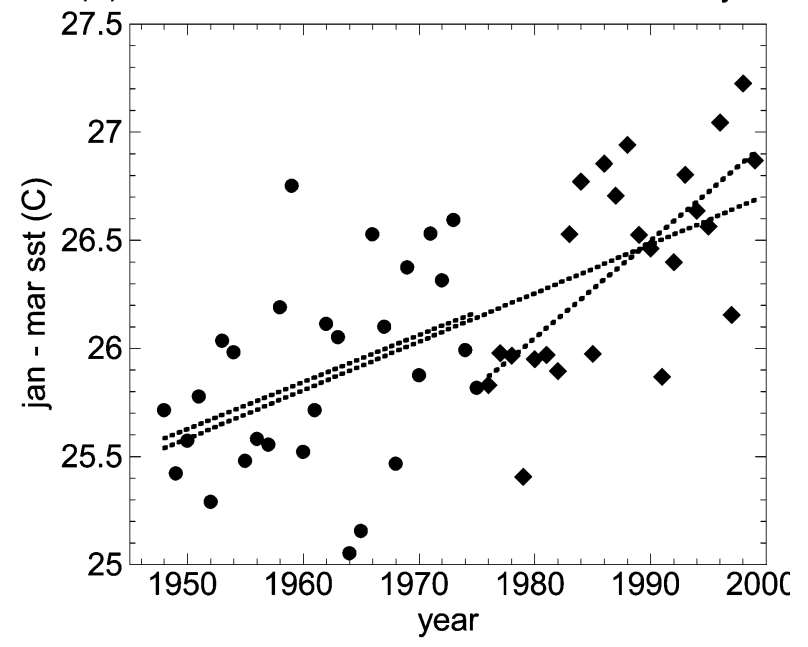

parison is impossible, however, because the period of study was different and they examined annual mean discharges.

Figure $11 \mathrm{c}$ is equivalent to Fig. 11a except that the quantity plotted is an index of SST centered on the area of maximum correlation shown in Fig. 7. The figure displays a trend that is qualitatively similar to the rainfall trend; the trend is larger from 1976 to 1999 than from 1948 to $1975\left(0.045^{\circ} \mathrm{C} \mathrm{yr}^{-1}\right.$ versus $\left.0.022^{\circ} \mathrm{C} \mathrm{yr}^{-1}\right)$, and explains more variance in the later period $(45 \%$ versus $15 \%)$.

While the coincidence of the timing of the trends in the two time series does suggest the possibility of a cause-and-effect relationship (or of a mutual cause), it is difficult to make a case with essentially 2 degrees of freedom. It can be argued that if there is an interannual relationship aside from the trend, and then if there is a trend in the causal field, it should result in a trend in the respondent field. The simultaneous correlations between rain and SST during the first and second periods are 0.61 and 0.57 , and the correlation over the entire period is 0.62 , but these calculations still include the trends in both SST and rainfall.

Figure 12 shows the simultaneous, SST leading (by 1 month) and SST lagging correlations for each 21-yr segment of the record, but with the trend removed from each segment. The correlations are always positive, with generally larger magnitudes when SST lags rainfall. By no means are all the segments independent, but the fact that the correlation for almost every segment exceeds the 95\% level for a two-sided $t$ test when SST lags rainfall supports a hypothesis that the two trends are linked by more than coincidence.

Figure 13a shows JFM average low-level wind vectors for 1976-81. Northeasterly winds prevail in the region of the observed SST trend, which are associated with the South Atlantic high. The difference (1994-99 minus 1976-81) reveals a weakening of the mean winds around the periphery of the high (Fig. 13b), where mean winds are strongest. A local maximum in wind speed decrease is located near the maximum in SST trend. The weakening of the wind seems to be somewhat consistent with an EOF analysis of sea level pressure over the South Atlantic by Venegas et al. (1998). By using anomalies from monthly means they found a mode that describes variations in the strength of the South Atlantic

FIG. 11. JFM rainfall (in $\mathrm{mm}$ season $^{-1}$ ) from gridded southern Brazil rain index, modified such that only stations with at least 48 yr data from 1948-99 were included in the gridded fields from which index was made, vs year. Filled circles represent years 1948-75. Filled squares represent years 1976-99 (which is the same period shown in Fig. 3b). Dashed curves represent linear, least squares fits for segments for 1948-75, 1976-99, and 1948-99. (b) As in (a) except ordinate is average JFM discharge at Salto Caxias, on the Iguazú River, near the confluence with the Paraná. (c) As in (a) except that ordinate is an index of average SST $\left(21.9^{\circ}-27.6^{\circ} \mathrm{S}\right.$ on a Gaussian grid, $\left.28.2^{\circ}-41.2^{\circ} \mathrm{W}\right)$ 


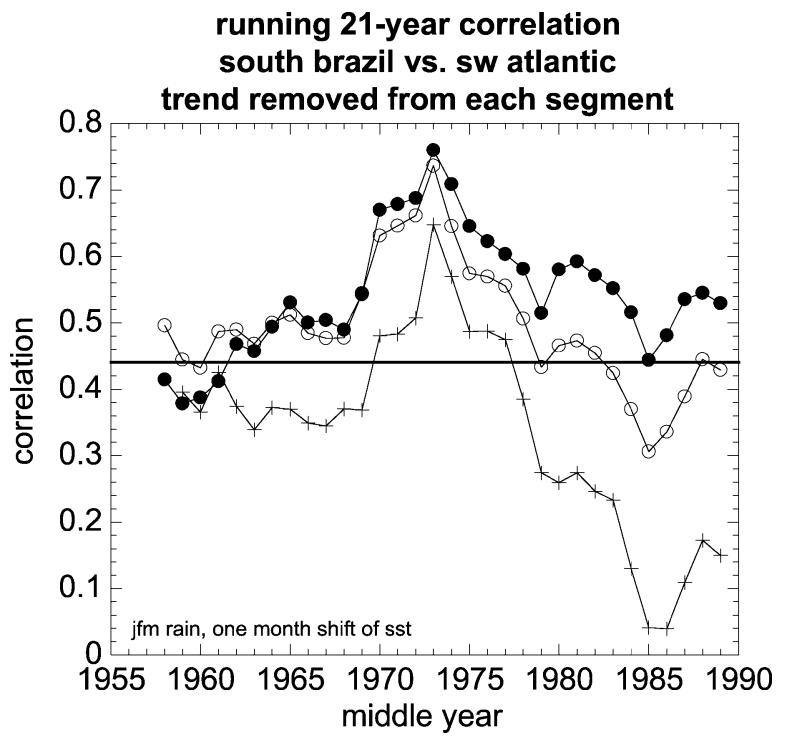

FIG. 12. Correlation for each 21-yr segment between JFM southern Brazil rainfall and southwest Atlantic SST indices. Each 21-yr segment has been detrended. Open circles depict simultaneous correlation, filled circles depict SST lagging by 1 month (FMA), and crosses depict SST leading by 1 month (DJF). Horizontal line represents $95 \%$ level of statistical significance, using a two-sided $t$ test with 19 degrees of freedom.

high. This mode exhibits a negative trend beginning in about 1976, although the series ends in 1992 and the last few years are not indicative of a trend.

The observed increase in SST is qualitatively consistent with the observed change in wind in a number of different ways. A reduction in speed will reduce evaporation at the surface and mixing above the thermocline. Reduced mixing will reduce entrainment at the thermocline. Both of these processes will result in warmer SSTs than in seasons with stronger mean winds. Furthermore, the mean wind is parallel to the coast, and so the net Ekman transport is away from the coast, causing coastal upwelling and surface cooling. The Ekman transport is lessened along with a reduction in mean winds, resulting in warmer SST.

\section{Summary and conclusions}

There has been a large positive trend in southern Brazil precipitation during JFM from 1976 to 1999. It is more than twice as large as the trend from 1948-75, although that too is positive. The trend is largest in the months of January and February. From 1976 to 1999 the trend results from an increase in the number of days with precipitation and from larger amounts per precipitation event, and not from a change in the timing of the rainy season. Consistent with this, the number of extreme events (defined here as events of more than 100 $\mathrm{mm}$ in 1 day) at stations more than doubled in the last $6 \mathrm{yr}$ of the period compared to the first $6 \mathrm{yr}$.

As with much of southern South America, the dom-
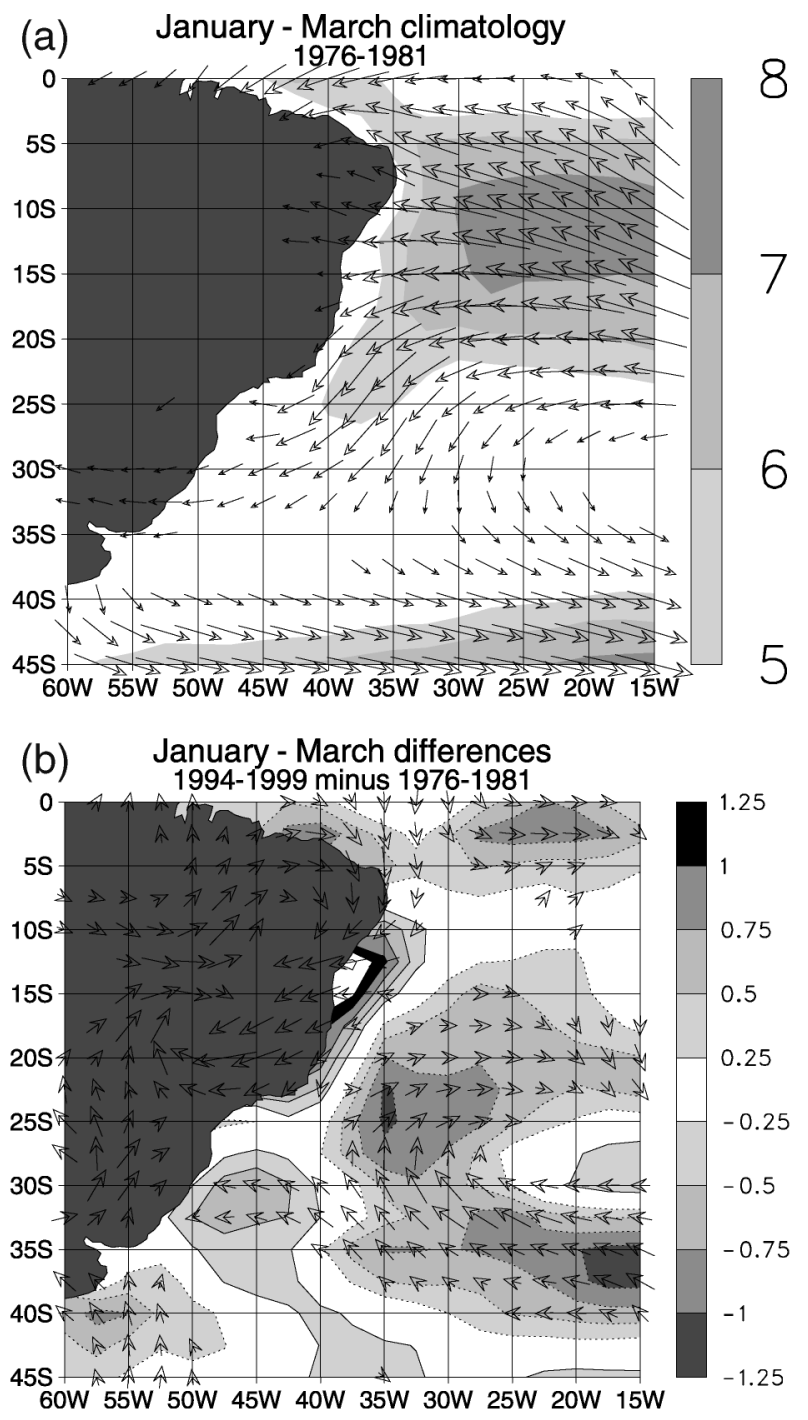

FIG. 13. (a) Mean JFM vector winds and speed at 0.995 sigma for 1976-81. Vectors are plotted for speeds above $2 \mathrm{~m} \mathrm{~s}^{-1}$. (b) Difference of vector winds and speed for JFM 1976-81 minus 1994-99. Vector differences are plotted if speed change is more than $0.5 \mathrm{~m} \mathrm{~s}^{-1}$.

inant upper-level height pattern associated with rainfall in the area of the observed trend is one of a wave train curving northward around the Andes from the midlatitudes of the Pacific. There is no obvious strengthening of the wave train during the period of record; in fact, there is a zonally oriented increase to the south of the continent.

In the subtropical southwestern Atlantic Ocean there is a trend in SST that appears to be related to the trend in rainfall. It too displays a marked increase in the trend from 1976-99 compared to 1948-75.

When the trend is removed from each overlapping 21-yr segment the correlations are always positive, suggesting that since there is a relationship between rainfall and SST in the absence of a trend, then a trend in one field will be related to a trend in the other. The rela- 
tionship is generally strongest when SST lags rainfall by 1 month (JFM rainfall versus FMA SST). In this case the 21-yr segments explain between $15 \%$ and $55 \%$ of the variance, and all but four of the segments are judged to be statistically significant.

A comparison of surface winds for JFM 1976-81 and 1994-99 shows that the winds associated with the South Atlantic high have weakened with time, including winds above the area with a strong positive trend in SST. Weakened surface winds above the SST should result in an increase in SST.

We speculate that the SACZ has shifted slightly southward with time (a negative trend, not statistically significant, on the northern flank, and a positive trend on the southern flank). A southward movement of the mean position of the SACZ would reduce cloudiness at the point of the SST trend, leading to warming by increased solar insolation as well.

Finally, it appears that the southward shift of the SACZ has influenced both rainfall and SST, rather than the rainfall anomalies directly forcing SST through a change in circulation. One may further speculate that changes in the position or strength of the South Atlantic high are the cause of the southward shift of the SACZ, but the dynamical origins of the SACZ are still open to debate (e.g., Kodama 1993; Figueroa et al. 1995; Liebmann et al. 1999).

Acknowledgments. Thanks to Toshi Shinoda (NOAACIRES Climate Diagnostics Center) for help in understanding the SST-rainfall linkage. We wish to thank the following agencies for providing data that made this project possible: Agência Nacional de Águas (Brazil), Agência Nacional de Energia Elétrica (Brazil), UTE Uruguay, CTM Salto Grande, Servicio Meteorologico Nacional de Argentina, Servicio Meteorologico Nacional de Paraguay, Servicio Meteorologico Nacional de Uruguay, FUNCEME (Ceará, Brazil), Sistema Meteorologico do Paraná (Paraná, Brazil), DAEE (São Paulo, Brazil), Administración Provincial de Agua (Chaco Province, Argentina), Ministerio del Ambiente y los Recursos Naturales (Venezuela), Meteorologische Dienst Suriname, MÉTÉO-France, and the National Climatic Data Center (United States). We wish to thank the InterAmerican Institute for Global Change Research (IAICRN-055) for providing funds to allow collaboration between the South American and United States investigators. We also wish to acknowledge the CLIVARPACS Program of NOAA-OGP.

\section{REFERENCES}

Barros, V., M. E. Castañeda, and M. Doyle, 2000: Recent precipitation trends in southern South America east of the Andes: An indication of climatic variability. Southern Hemisphere Paleo and Neo-Climates, P. P. Smolka and W. Volkheimer, Eds., SpringerVerlag, 187-206.

Berbery, E. H., and V. R. Barros, 2002: The hydrological cycle of the La Plata basin in South America. J. Hydrometerology, 3, 630-645.

Camilloni, I. A., and V. R. Barros, 2003: Extreme discharge events in the Paraná River and their climate forcing. J. Hydrology, 278, 94-106.

Chiew, F., P. Whetton, and T. McMahon, 1995: Detection of climate changes in recorded runoff volumes in south-east Australian rivers. Int. J. Climatol., 13, 643-653.

Chow, V. T., D. R. Maidment, and L. W. Mays, 1988: Applied Hydrology. McGraw-Hill, 572 pp.

Doyle, M. E., and V. R. Barros, 2002: Midsummer low-level circulation and precipitation in subtropical South America and related sea surface temperature anomalies in the South Atlantic. J. Climate, 15, 3394-3410.

Figueroa, S., P. Satyamurti, and P. L. Silva Dias, 1995: Simulation of the summer circulation over the South American region with an Eta coordinate model. J. Atmos. Sci., 52, 1573-1584.

Genta, J. L., G. Perez-Iribarren, and C. R. Mechoso, 1998: A recent increasing trend in the streamflow of rivers in southeastern South America. J. Climate, 11, 2858-2862.

Grimm, A. M., 2003: The El Niño impact on the summer monsoon in Brazil: Regional processes versus remote influences. J. Climate, 16, 263-280.

— , V. R. Barros, and M. E. Doyle, 2000: Climate variability in southern South America associated with El Niño and La Niña events. J. Climate, 13, 35-58.

Kodama, Y.-M., 1993: Large-scale common features of sub-tropical convergence zones (the Baiu frontal zone, the SPCZ, and the SACZ). Part II: Conditions of the circulations for generating the STCZs. J. Meteor. Soc. Japan, 71, 581-610.

Liebmann, B., and J. A. Marengo, 2001: Interannual variability of the rainy season and rainfall in the Brazilian Amazon basin. $J$. Climate, 14, 4308-4318.

Liebmann, B., G. N. Kiladis, J. A. Marengo, T. Ambrizzi, and J. D. Glick, 1999: Submonthly convective variability over South America and the South Atlantic convergence zone. J. Climate, 12, 1877-1891.

Liebmann, B., G. N. Kiladis, C. S. Vera, A. C. Saulo, and L. M. V. Carvalho, 2004: Subseasonal variations of rainfall in South America in the vicinity of the low-level jet east of the Andes and comparison to those in the South Atlantic convergence zone. J. Climate, 17, 3829-3842.

Marshall, G. J., 2002: Trends in Antarctic geopotential height and temperature: A comparison between radiosonde and NCEPNCAR reanalysis data. J. Climate, 15, 659-674.

— 2003: Trends in the southern annular mode from observations and reanalysis. J. Climate, 16, 4134-4143.

Mo, K. C., X. L. Wang, R. Kistler, M. Kanamitsu, and E. Kalnay, 1995: Impact of satellite data on the CDAS-reanalysis system. Mon. Wea. Rev., 123, 124-139.

Pisciottano, G., A. Díaz, and G. Gazes, 1994: El Niño-Southern Oscillation impact of rainfall in Uruguay. J. Climate, 7, 12681302.

Robertson, A. W., and C. R. Mechoso, 1998: Interannual and decadal cycles in river flows of southeastern South America. J. Climate, 11, 2570-2581.

Salio, P., M. Nicolini, and A. C. Saulo, 2002: Chaco low-level jet events characterization during the austral summer-season. $J$. Geophys. Res., 107 (D24), 4816-4832.

Solow, A. R., 1987: Testing for climate-change: An application of the two-phase regression model. J. Climate Appl. Meteor., 26, 1401-1405.

Tossini, L., 1959: Sistema hidrográfico y cuenca del Río de la Plata. Contribución al estudio de su regimen hidrológico. Anales de la Sociedad Cientifica Argentina, CLXVII (3-4), 41-64. (The hydrographic system and the La Plata River basin. A contribution to the study of its hydrological regime. Proc. Argentine Sci. Soc. March April 1959, III and IV, Vol. CLXVII (3-4), 41-64.

Venegas, S. A., L. A. Mysak, and D. N. Straub, 1997: Atmosphereocean coupled variability in the South Atlantic. J. Climate, 10, 2904-2920. 